Brit. J. vener. Dis. (1961), 37, 126.

\title{
PRESENT SITUATION OF GONORRHOEA IN ITALY*
}

\author{
BY \\ G. TASSI
}

Rome

Gonococcal infection in Italy is mainly of the acute type affecting the genitalia, the articular and ocular forms being very rare. The disease is more widespread in urban centres than rural areas and is more frequent among men than women.

Data concerning the incidence of venereal disease are drawn from notifications by the Clinics controlled by the Ministry of Health. During recent years the number of cases of gonorrhoea among both the civil population and the armed forces, has tended to stabilize, in contrast to the rising curve of syphilis notifications.

The facilities provided by the State for the treatment of venereal disease are laid down in the law of July 25, 1956; in respect of gonorrhoea the most pertinent paragraphs are as follows:

(1) Compulsory treatment, free of charge, of any person suffering from venereal disease.

(2) Notification of cases of venereal disease, without revealing the identity of the patient, but including details concerning diagnosis, sex, age, residence, and, when possible, information on the source of infection.

Any physician diagnosing a case of venereal disease is obliged to inform the patient of the nature of the disease, of the fact that it is contagious, of the obligation to undergo treatment, and of the facilities available by law.

Diagnosis is based principally on smears. Since the introduction of the sulphonamides, the clinical symptoms of gonorrhoea have mainly been limited to genital manifestations: urethritis in men, urethrovaginitis and infection of the vulvar glands in adult women, and vulvo-vaginitis in prepubertal females. In men, serious complications are extremely rare, but in women there is a certain incidence of metritis

* Paper read at the European Symposium of the I.U.V.D.T. at Cracow, Poland, in September, 1960. and of salpingo-ovaritis because the female genital apparatus favours the concealment of the first external signs of gonorrhoea, which therefore pass unperceived.

In view of the extreme lability of cultures of $N$. gonorrhoeae in vitro $\left(\mathrm{pH}\right.$, temperature, $\mathrm{CO}_{2}$ environment, composition, and modification of culture media), use is made in Italy of the Microbiology Institutes which exist in all the principal towns. The most commonly used culture media are of the solid type, composed of agar, liver, serum, and horse blood (called "D.V." D'Antona-Valansin media). Liquid media are used less frequently; the only difference in preparation is that broth is substituted for agar. Experience so far has shown that $N$. gonorrhoeae is very sensitive not only to penicillin but also to many other antibiotics (streptomycin, tetracycline, etc.), and resistance to antibiotics has so far been very slight. In nearly all cases of antibiotic-resistant urethritis, it has been noted that $N$. gonorrhoeae has been accompanied by other bacteria or that other organisms have been superimposed as a later complication. In Italy, the Higher Institute of Health (Instituto Superiore di Sanita) and the University Microbiology Laboratories act as highlevel diagnostic centres.

The treatment of gonorrhoea is not standardized, but varies according to the personal experience of each specialist. Doses range from 1.5 to 3 million units of procaine penicillin or of benzathine penicillin at the rate of one million units per day in two doses. For the treatment of associated organisms, sulphonamides are prescribed side by side with the antibiotics. Repository sulphonamides such as sulphametoxy-pyridazine are generally used, at the following rate: first day $1 \mathrm{~g}$. in two doses, followed by $1.5 \mathrm{~g}$. in one dose every 24 hours for about a week, for both men and women.

Lectures are sometimes organized in different 
social circles (schools, factories, workers' associations, peasants' reunions, etc.) in order to keep the public informed about the danger of venereal disease; on these occasions booklets are distributed containing information and instruction relating to these diseases. It must be remembered that certain social factors make it difficult to achieve complete success in the control of venereal disease. These factors include the increase in social and sexual promiscuity; the emancipation and precocity of both sexes; the refusal on the part of some women to content themselves with a mediocre existence, which leads to a desire for luxury and hence to the easy money to be earned by prostitution; the postponement of marriage for the sake of liberty or for financial reasons.

\section{Conclusions}

In order to combat the danger of venereal disease successfully, the following procedures are necessary:

(a) To improve the systems of statistical evaluation, and to obtain the co-operation of private practitioners in tracing contacts who now very often escape detection;

(b) To organize at some high-level centre research into the pathogenic agents of all sexual diseases and so to improve diagnosis;

(c) To establish a standardized treatment schedule so as to obtain a systematic evaluation of the sensitivity of the gonococcus to antibiotics;

(d) To counter the tendency among patients to administer self-treatment with penicillin-such treatment being usually erroneous or incomplete.

\section{Summary}

Notifications from the clinics to the Italian Ministry of Health show that the incidence of gonorrhoea is stable, unlike that of early syphilis, which is increasing. Venereal disease is notifiable without disclosure of the patient's identity, and free treatment is compulsory. $N$. gonorrhoeae remains very sensitive to antibiotics in Italy, but specified social factors prevent the successful control of venereal disease.

\section{L'état actuel de la blennorragie en Italie}

\section{Résumé}

D'après les notifications des cliniques au Ministère de la Santé italien, l'incidence de la gonorrhée est constante, mais celle de la syphilis peu avancée augmente. Les maladies vénériennes sont notifiables, mais le malade reste anonyme, et le traitement est gratuit et obligatoire. En Italie, $N$. gonorrhoea reste très sensible aux antibiotiques, mais certains facteurs sociaux empêchent le contrôle effectif des maladies vénériennes. 